\title{
Роль ценностных ориентаций молодых тувинцев в пространственном развитии Республики Тыва*
}

\author{
Ольга А. Персидская \\ Институт философии и права Сибирского отделения Российской академии наук, \\ Российская Федерация
}

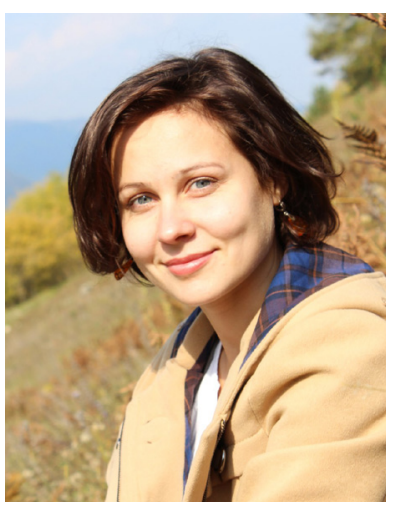

В работе пространственное развитие Республики Тыва рассматривается как проблема развития общества и экономики региона, решаемая с учетом культурных ценностей коренного населения республики, составляющего более $80 \%$ всего населения. То есть речь идет об учете этнокультурной составляющей в трактовке пространственного развития. Основной акцент сделан на ценностно обусловленном экономическом поведении. Обосновывается, что такой анализ позволяет выявить основания экономического поведения большинства населения и зафиксировать специфику современного этноэкономического уклада Тувы. Поэтому такой подход эвристичен для разработки стратегий пространственного развития региона.

Эмпирической базой исследования выступили данные социологического опроса тувинской молодежи, проведенного в Туве в 2012 г. представителями новосибирской школы этносоциологии под руководством Ю. В. Попкова. Анализ данных выполнен на основе переосмысления автором некоторых параметров культуры Г. Хофстеде. Сделаны заключения о специфике системы ценностей молодежи Тувы, которые позволили охарактеризовать культуру тувинцев как коллективистски ориентированную, феминную и с высокой степенью избегания неопределенности.

Проведенный анализ позволил дополнить портрет Тувы чертами, важными как для выявления ее социокультурной специфики, так и для решения задачи по учету этнокультурной составляющей в социально-экономическом развитии субъектов Российской Федерации. Подчеркивается, что выявление социокультурной специфики позволяет искать точки роста для программ экономического развития конкретных регионов. Сформулированы рекомендации, касающиеся характеристик организационной этики и особенностей менеджмента предприятий в Туве.

Ключевые слова: молодежь; Тува; тувинцы; ценности культуры; пространственное развитие; этноэкономический уклад; кросскультурный подход

"Работа выполнена по программам фундаментальных научных исследований, определяемых Президиумом РАН.

\section{Для цитирования:}

Персидская О. А. Роль ценностных ориентаций молодых тувинцев в пространственном развитии Республики Тыва [Электронный ресурс] // Новые исследования Тувы. 2019, № 3. URL: https://nit.tuva.asia/nit/article/view/863 (дата обращения: дд.мм.гг.). DOI: 10.25178/nit.2019.3.4

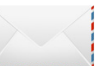

Персидская Ольга Алексеевна - младший научный сотрудник отдела социальных и правовых исследований Института философии и права Сибирского отделения Российской академии наук. Адрес: 630090, Россия, г. Новосибирск, ул. Николаева, д. 8. Тел.: +7 (383) 330-22-40. Эл. адрес: olga alekseevna@mail.ru

ORCID ID: 0000-0002-6821-4692

Persidskaia Olga Alekseevna, Junior Research Fellow, Department of Social and Legal Studies, Institute of Philosophy and Law, Siberian Branch, Russian Academy of Sciences. Postal address: 8 Nikolaeva St., 630090 Novosibirsk, Russian Federation. Tel.: +7 (383) 330-22-40.E-mail: olga_alekseevna@mail.ru 


\title{
The role of value orientations of young Tuvans in the spatial development of the Republic of Tuva"
}

\author{
Olga A. Persidskaya \\ Institute of Philosophy and Law, SB RAS, Russian Federation
}

\begin{abstract}
The paper considers the spatial development of the Republic of Tyva as a problem of the social and economic development of the region. This issue can be resolved with respect to cultural values of the indigenous population of the republic, who accoubt for more than $80 \%$ of its total population. More specifically, the ethnocultural component should be placed in the context of economic interpretation of spatial development. The focus is made on value-driven economic behavior. Such analysis makes it possible to identify the reasons for the economic behavior of most of the population and to indicate peculiarities of the modern ethnoeconomic structure of Tuva. Therefore, this approach is heuristic for developing strategies for spatial development of the region.

The research is based on the data of a sociological survey of Tuvan youth conducted in Tuva in 2012 by representatives of the Novosibirsk school of ethnosociology under the supervision of Yu. V. Popkov. The data analysis is based on the author's reimagination of some parameters of culture as developed by G. Hofstede. Therefore, we can categorize the culture of Tuvan youth value system as collectivist-oriented, feminine, with a high degree of avoiding uncertainty.

The analysis made it possible to complement the portrait of Tuva with features that are important both for identifying its sociocultural peculiarities and for solving the problem of how to take account of the ethnocultural component within the general socioeconomic development of Russia's constituent subjects. The article emphasizes that identification of sociocultural peculiarities helps locate potential "growth areas" for the programs of economic development of specific regions. Also formulated are some recommendations concerning the characteristics of institutional ethics and details of enterprise management in Tuva.
\end{abstract}

Keywords: youth; Tuva; Tuvans; cultural values; spatial development; the determinants of spatial development; ethnoeconomic structure; cross-cultural approach

"The article was written under the aegis of programs of fundamental research established by the Presidium of the Russian Academy of Sciences.

Persidskaia O. A. The role of value orientations of young Tuvans in the spatial development of the Republic of Tuva. The New Research of Tuva, 2019, no. 3 [online] Available at: https://nit.tuva.asia/nit/article/view/863 (access date ... ). DOI: 10.25178/nit.2019.3.4

\section{Введение}

Изучение особенностей пространственного развития регионов и поиск стратегий повышения его эффективности принято связывать с областью экономических исследований. По нашему мнению, хотя экономический подход обладает значительной методологической и методической базой по разработке данной проблематики и в его рамках достигнуты значимые и для теоретического развития, и для управленческой практики результаты, актуальным является также взгляд на проблему пространственного развития с точки зрения других дисциплин, позволяющий найти новое концептуальное и содержательное наполнение темы.

В данной работе предпринята попытка взглянуть на пространственное развитие региона - Республики Тыва - с точки зрения этносоциологии с методологической опорой на кросс-культурный подход. Цель исследования - выявление взаимосвязи системы этнокультурных ценностей с пространственным развитием региона. Задачи исследования: обосновать механизм влияния структуры ценностей на экономическое поведение; на основе анализа данных массового социологического опроса молодежи Тувы выявить систему ценностей тувинцев; дополнить социокультурный портрет Тувы характеристиками, позволяющими учесть этнокультурный фактор в социально-экономическом развитии республики. 
Методологической основой работы выступает кросс-культурная интерпретация культурных ценностей Г. Хофстеде, позволяющая рассматривать культурные ценности как основу культурно обусловленных форм экономического поведения. Таким образом, выявление структуры ценностей этнических групп, населяющих регион, может стать значимым шагом для решения задачи, связанной с необходимостью учета этнокультурных факторов в социально-экономическом развитии субъектов Российской Федерации.

В качестве источниковой базы исследования выступают публикации авторов, посвятивших свои исследования методологии и методикам кросс-культурного подхода в исследовании ценностей (Г. Хофстеде, Р. Инглхарт, Ф. Тромпенаарс, Ш. Шварц); вопросам этноэкономического развития регионов Российской Федерации (В. Я. Ахметов, Г. И. Бердникова, В. В. Браткова, Н. В. Гонтарь, Н. А. Дегтярева, Н. Н. Киселева, Е. М. Колмакова, О. В. Печура, Г. И. Шагибалова идр.); социально-экономическим проблемам Тувы и перспективам ее модернизации (Г. Ф. Балакина, Д. Ф. Дабиев, У. М. Дабиева, А. Ч. Килдыгай и др.) с акцентом на системе ценностей тувинцев (М. Ш. Абдулаева, З. В. Анайбан, Ч. К. Ламажаа, Е. А. Тюгашев, Ю. В. Попков и коллектив авторов ИФПР СО РАН). Эмпирической базой работы стали обработанные автором данные массового социологического опроса, проведенного в Республике Тыва в 2012 г. под руководством д. филос. н., проф. Ю. В. Попкова сотрудниками Института философии и права СО РАН (г. Новосибирск).

\section{Роль этнической культуры в развитии экономики}

В обновленном варианте Стратегии государственной национальной политики Российской Федерации на период до 2025 г. (далее - Стратегия) в качестве обязательных к выполнению задач обозначены «учет этнокультурного фактора при обеспечении сбалансированного, комплексного и системного развития субъектов Российской Федерации и муниципальных образований» и «формирование гибкой системы расселения населения, учитывающей многообразие региональных и национальных укладов жизни» (Стратегия ... , Электр. ресурс). Решение таких задач наталкивается на проблему, связанную с тем, что различия в уровне экономического развития регионов увеличивают опасность возникновения региональных кризисов и затрудняют проведение единой социально-экономической политики (Киселева, Браткова, 2014: 131), что актуализирует необходимость разработки управленческих стратегий, масштабированных не в федеральных, а в региональных и локальных границах.

Пространственное развитие региона - это процесс, детерминируемый изменениями в организации обустройства занимаемой регионом территории и распределением мест обитания и характера деятельности основных социальных и профессиональных слоев общества, вносящих наиболее значимый вклад в его прогрессивное развитие (Колмакова Е., Колмакова И., Дегтярева, 2018: 31). В историко-экономических исследованиях в качестве детерминант пространственного развития региона рассматриваются природные условия и специфика исторических этапов хозяйственного освоения его территории, которые обуславливают большую или меньшую эффективность складывающихся региональных хозяйственно-автохтонных систем (Паникарова, Власов, Чебодаева, 2011: 53). В части исследований, прямо или косвенно связанных с пространственным развитием регионов, акцентируется значимость геополитического фактора, например, выделяются более экономически развитый «центр» и отстающая по социально-экономическим показателям «периферия» (Аниканов, Степанов, Сусоколов, 1999: 10-11).Реже исследователи выходят на взаимосвязь проблемы неравномерности пространственного развития регионов со спецификой экономических укладов населяющих их этнических групп (Ахметов, Бердникова, Шагибалова, 2010; Гонтарь, 2015: Электр. ресурс).

По итогам сравнительных исследований регионов ряда параметров, среди которых интенсивность хозяйственной активности и финансовой самодостаточности, привлекательность региона как места проживания, степень развитости в нем инновационной активности и др., Н. Н. Киселева и В. В. Браткова отмечают, что на общероссийском фоне по совокупности показателей уступают республики Северо-Кавказского федерального округа, Мордовия, Алтай, Бурятия, Тыва, то есть так называемые национальные или «этнические» регионы. Как указывают авторы, в данных регионах практически «отсутствуют условия и стимулы самостоятельного территориального развития» (Киселева, Браткова, 2014: 131). Экономический уклад этнических регионов слабо восприимчив к процессам модернизации по западному типу. Эта ригидность этнических экономик связана со сложным комплексом причин, среди которых преимущественное распространение в домохозяйствах традиционных, чаще аграрных форм хозяйственной деятельности, преобладание кустарных ремесел и надомного ручного труда, высокий авторитет неформальных институтов, экстенсивный тип занятости с использованием сырьевой хозяйственной инфраструктуры, низкая социальная и территориально-пространственная мобильность населения и малоразвитость обмена (Овчинников, Колесников, 2006: 147-148). 
Соглашаясь с некоторыми выводами таких исследований, связанными с подчеркиванием определяющей роли этнических экономик в организации жизни значительной части жителей национальных регионов, мы все же считаем, что разница социально-экономических показателей регионов, акцентированная в Стратегии как проблема, может быть рассмотрена также и с другой стороны: этнические особенности могут и должны выступить как точки роста для эффективных программ экономического развития конкретных регионов. В этом смысле игнорирование этнической составляющей в анализе перспектив пространственного развития равноценно потере значимой части потенциала развития экономического пространства.

Мы считаем, что поддержка исторически сложившихся этноэкономических укладов и их адаптация к современным экономическим условиям важна, так как позволяет раскрыть потенциал роста экономик этнических регионов. При этом важно отметить, что этноэкономический уклад обладает высокой степенью жизнеспособности на индустриальных и даже постиндустриальных стадиях общественного развития за счет высокой степени адаптивности своих форм.

К механизмам, позволяющим в современных условиях раскрыть потенциал этноэкономического уклада той или иной этнической группы, относят: разработку этноэкономических профилей регионов, учитывающих специфику исторически и культурно имманентных для населяющих его этнических групп форм хозяйствования; формулирование и совершенствование нормативно-правовой базы по внедрению элементов этноэкономического уклада; создание социально-экономических и организационных предпосылок для формирования кластера мелких этнически-ориентированных товаропроизводителей, развивающих сеть отраслей традиционной этноэкономики; стимулирование развития потребительской кооперации в сфере переработки и реализации сельскохозяйственной продукции и др. (см.: Персидская, 2017). Также, по нашему глубокому убеждению, важное значение в поиске эффективных стратегий этноэкономического развития играет выявление и учет ментальных, ценностных оснований культур, носителями которых являются представители разных этнических групп, населяющих регион. В социогуманитаристике существенную поддержку находит точка зрения о том, что экономические уклады в значительной степени являются порождением этнической среды, а не только стратегий рационального экономического поведения, так как этнические культуры, на ментальном уровне «программирующие» активность своих носителей, оказывают влияние на их экономическое поведение через ценности (см: Печура, 2009; Персидская, 2012).

Об особенностях системы ценностей тувинцев сказано достаточно много. Так, Ч. К. Ламажаа в своей монографии «Тува между прошлым и будущим» отмечает такие ключевые черты «резко-континентальной культуры» тувинцев, как приверженность своим этническим корням, выражающаяся в тесной связи с родом и семьей, подчеркиваемая гордость за достижения своего народа, значимость кочевого образа жизни, музыкальность, образность мышления, близость к природе и ее циклам. Отдельно автор акцентирует внимание на том, что существенное влияние на самобытность мировоззрения народа Тувы оказывает формирование культуры в некоторой изоляции «внутрисаянья», в условиях сложного религиозного синкретизма и смешения различающихся культурных пластов (Ламажаа, 2011). Ю. В.Попков и Е.А. Тюгашев на основе анализа данных социологических опросов фиксируют такие ценностные ориентации у тувинцев, как приверженность коллективизму, приоритет патернализма, важность комплексного выражения собственной этничности и др. (Попков, Тюгашев, 2010).

Однако, как отмечают Д. Ф. Дабиев и У. М. Дабиева, культурные и религиозные ценности тувинцев оказались существенно трансформированы в период Тувинской Народной Республики и в советское время (Дабиев, Дабиева, 2015). В то же время, реакция тувинского населения на социально-экономические трансформации пост-советского периода показала глубокую укорененность традиционной основы в коллективном сознании рассматриваемой этнической группы. Как отмечают Ч. К. Ламажаа и М. Ш. Абдулаева, «феномены архаизации здесь (в Туве и ряде других этнических регионов Сибири: на Алтае, в Бурятии, Хакасии. - О. А.) выразились в первую очередь в натурализации хозяйственной деятельности, в актуализации архаических представлений о земле как территории коллективного пользования родов и отторжении идеи частной собственности на землю; в массовом возрождении архаических семейнородовых объединений и правил взаимопомощи; в возрождении значения скота как ценности, элемента богатства, мерила материального благополучия» (Ламажаа, Абдулаева, 2014: 69-70). Обращение к архаизированным социальным практикам, переплетенным с их современным неотрадиционным переосмыслением, подтверждает, на наш взгляд, идею о том, что социально-экономический прогресс Тувы затруднителен без реализации моделей экономики, опирающихся на исторически сложившиеся этноэкономические уклады. 


\section{Возможности кросскультурного подхода в выявлении ценностно обоснованного экономического поведения}

Выявление и сравнение ценностей разных культур (в том числе этнических) является одной из целей кросскультурного направления в социогуманитаристике. В рамках кросскультурного подхода этническая группа воспринимается не обособленно, а в системе взаимодействия культур, цивилизаций, мира в целом. Выход за рамки документирования культурных различий с целью понять, какие ценностные переменные лежат в основе культур, привел к складыванию специфической методологии кросскультурных исследований. В ее основе лежит предположение, что все культуры могут быть дифференцированы в соответствии с их положением на шкалах, отражающих определенный набор ценностных дилемм. Влияние культурных ценностей на социально-экономическое развитие изучалась в работах Ф. Тромпенаарса, Ш. Шварца, Р. Инглхарта и других исследователей (см.: Тромпенаарс, Хэмпден-Тернер, 2004; Schwartz, 1992; Инглхарт, Вельцель, 2011).

Эмпирические выводы данной работы основаны на методологии Г. Хофстеде, нидерландского исследователя, который на основе результатов факторного анализа, проведенного на широчайшем эмпирическом материале, сформулировал пять ценностных шкал (Hofstede, 1980, 1998). В логике Г. Хофстеде, основу системы ценностей культуры составляет статистически обобщенный выбор большинством ее представителей того или иного полюса из следующих пяти шкал-дихотомий: (1) индивидуализм или коллективизм, (2) высокий или низкий уровень избегания неопределенности, (3) большая или малая дистанция по отношению к власти, (4) феминность или маскулинность, (5) долгосрочная или краткосрочная ориентация целей представителей культуры. Первый показатель разделяет культуры на индивидуалистические и коллективистские; второй определяет потребность в формальных правилах и уровень терпимости к нетрадиционным идеям; третий указывает степень, в которой общество одобряет неравномерное распределение власти в институтах и организациях; четвертый основан на склонности большинства представителей культуры к ценностям экономического развития и роста дохода (маскулинные культуры) или к повышению качества жизни и улучшению отношений с людьми (феминные культуры); наконец, пятый раскрывает динамизм культуры: дальность горизонта планирования, к которой склонны большинство представителей конкретной культуры. Выявление ценностного полюса, к которому тяготеет исследуемая культура по каждой из перечисленных шкал, в результате дает сложную картину специфической системы ценностей. В соответствии с методикой Г. Хофстеде, эта система ценностей интерпретируется в терминах, описывающих стратегии поведения, в том числе, экономического, имманентно присущих культуре. Представляется, что такой анализ может быть полезен для выявления механизмов увеличения эффективности пространственного развития территорий, связанных с повышением бизнес-активности и умножением социального капитала.

\section{Ценности тувинской культуры в интерпретированной методологии Г. Хофстеде}

Насколько нам известно, исследований по методу Г. Хофстеде в Туве не проводилось, но имеются эмпирические данные, полученные в процессе исследований, проведенных по другим методикам, но с сопоставимыми результатами. Речь в частности идет об итогах работы, проведенной в 2012 г. сотрудниками Института философии и права СО РАН (г. Новосибирск) в рамках программы изучения ценностных ориентаций населения национальных республик Южной Сибири и сопредельных территорий (руководитель проекта - д. филос. н., проф. Ю. В. Попков, организатор опроса в республике канд. филос. н. С. А. Мадюкова, интервьюер - И. С. Тарбастаева). Исследование было проведено методом массового социологического опроса. В его основе лежала авторская методика дихотомически организованных ценностных предпочтений (подробное описание методики и результатов исследования см.: Евразийский мир, 2010: 212-291). Выполненный нами анализ методики позволил сделать заключение о значительном числе пересечений идей сибирских этносоциологов и Г. Хофстеде не только в методической части (которая касается представления о том, что ценностные предпочтения могут быть организованы в виде дихотомических противопоставлений), но, что важно, и в самом смысловом наполнении этих ценностных дихотомий. Это позволяет использовать результаты опроса 2012 г. для того, чтобы рассмотреть ценности тувинской культуры в горизонте методологии Г. Хофстеде.

Результаты исследования позволили сибирским этносоциологам доказать гипотезу о евразийском основании в системах ценностей разных этнических групп Сибири, а также Калмыкии, Казахстана и Монголии. Переосмысление полученных эмпирических данных, вдохновленное методологией Г. Хоф- 
стеде и осуществленное в данной работе, предпринято для того, чтобы использовать модель системы ценностей культуры для объяснения некоторых характеристик экономического поведения у тувинцев. Представляется, что анализ таких характеристик может открыть способы диагностики и повышения качества человеческого капитала и интенсификации бизнес-активности, что значимо для выявления стратегий пространственного развития Тувы, где тувинцы составляют большинство населения.

Итак, эмпирической базой данной работы послужили результаты массового социологического опроса, проведенного в Туве в 2012 г. Всего в опросе приняли участие 718 человек, все представители учащейся и работающей молодежи разных этнических групп. Так как выборка исследования была построена в соответствии с этнической структурой региона, большинство опрошенных - 612 чел. или 85\% опрошенных - являются тувинцами, и приведенная в данной статье статистика основана именно на их ответах. Возраст опрошенных на момент проведения исследования составлял от 16 до 27 лет, соответственно, сейчас, в 2019 г., этим людям от 23 до 34 лет. Можно предположить, что большинство из них в настоящее время являются участниками рынка труда в качестве экономически активной части населения. Так как система культурных ценностей является достаточно устойчивой структурой и ее основания мало изменчивы, стабильны - как в границах жизни отдельного человека, так и в рамках существования социальных групп - можно предположить, что суждения о ценностях, высказанные респондентами в 2012 г., сейчас являются реальными регуляторами экономического поведения части экономически активного, молодого населения Тувы, а поэтому актуальны. Именно руководствуясь этими соображениями, мы посчитали, что результаты данного исследования востребованы в настоящее время.

На имеющихся материалах опроса нам удалось найти способ проинтерпретировать только первые четыре из пяти вышеназванных шкал Г. Хофстеде. Следует оговорить, что интерпретация шкал Хофстеде весьма условна и наполнена набором эмпирических индикаторов, которые совпадают с указанными нидерландским социологом скорее по смыслу, чем по конкретному методическому содержанию.

Для выявления склонности опрошенных тувинцев к индивидуалистическим или коллективистским цеенностям был проведен анализ ответов на вопросы о коллективизме и индивидуализме и об их утилитарной значимости для личности. Результаты опроса показали, что на уровне общих представлений коллективизм видится опрошенным более привлекательным. Так, 78\% из них считают, что тувинскому народу более всего нужно чувство взаимопомощи, коллективизма, а не чувство индивидуализма, личной деловитости, свободы личности. Также абсолютное большинство опрошенных (72\%) поддержало идею о том, что для успешного развития тувинского народа следует развивать коллективную собственность. В то же время, на уровне анализа личностных ценностных ориентаций не все так однозначно: хотя сторонниками коллективистской идеи о том, что интересы народа (этнической группы) должны быть выше интересов личности, выступили 54\% респондентов, также значительное их число (46\%) поддержало индивидуалистическую установку: для них личные интересы человека находятся в приоритете по сравнению с интересами народа. Несмотря на это, мы все же склонны отнести тувинскую культуру скорее к коллективистским, а выявленную ориентацию почти половины опрошенных на предпочтение личных, а не общеэтнических интересов определить скорее не как ценность, а как стратегию выживания в современном мире, преимущественно основанном на законах рыночной экономики.

Интересно отметить еще одну явно коллективистскую черту тувинского национального характера, которую зафиксировали Г.Ф.Балакина и А.Ч. Кылгыдай: высокая значимость ценностей равенства и родства у них подчас выражается в повсеместно принятом «уравнительным распределении» благ в семье: считается, что более экономически успешный родственник должен разделить свой доход с менее успешными, оказывать им поддержку (Балакина, Кылгыдай, 2012: 75).

Приоритет коллективистских ценностей, выражающийся у тувинцев через значимость для них семейной идентичности, подчеркивает в своих публикациях Ч. К. Ламажаа. По мысли автора, модернизация в Туве может быть реализована наиболее эффективно, если будет сделана ставка не на развитие индивидуальных «я», а на коллективные «я» через воздействие на локальные семейные сообщества, так как «в характеристики идеального тувинца по сию пору входит ориентация на коллективистские ценности, в том числе он должен знать свою родословную, свое происхождение, как можно большее число родственников, соблюдать родовые традиции, бережно относиться к природе и почитать ее духов» (Ламажаа, 2011: 295). Высокая ценность семьи позволяет ей аккумулировать несколько значимых социальных функций: быть транслятором ценностей, выступать ячейкой экономического развития, быть агентом социально-политической активности.

По нашему мнению, степень избегания неопределенности можно зафиксировать, опираясь на выбор опрошенными ценностей свободы или порядка, стабильности или перемен и ориентации на сохра- 
нение или разрушения традиций ради прогресса общества. В целом, молодые тувинцы показали себя как общность с высоким уровнем избегания неопределенности: 70\% указали, что для страны важнее обеспечение общего порядка, а не личных свобод граждан, 64\% считают, что в жизни важнее стабильность и устойчивость, а не перемены и новизна, 76\% уверены, что новое следует строить с сохранением, а не разрушением традиций. То, что тувинцев следует отнести скорее к представителям культур с высоким уровнем избегания неопределенности, подтверждается и зафиксированной Г. Ф. Балакиной и А. Ч. Кылгыдай сниженной скоростью адаптации к условиям рынка у тувинской молодежи по сравнению с русской (Балакина, Кылгыдай, 2012: 74).

Дистанция власти проинтерпретирована нами как такое представление о роли государства для человека, в котором большой дистанции свидетельствуют выраженные ценности патернализма, а короткой противоположный, предполагающий большую индивидуальную свободу взгляд на систему отношений между гражданином и государством. Анализ данных показал, что среди опрошенных тувинцев нет явного преобладания той или иной позиции: 53\% считают, что рабочие места и условия жизни должно обеспечить государство (патерналистская установка), а человек должен хорошо трудиться, остальные полагают, что человек должен сам обеспечить себе работу и условия жизни, а государство - его защиту законами и справедливыми налогами. Косвенно о патерналистических установках тувинской молодежи свидетельствуют также упоминания об «иждивенческой психологии», о распространенности в массовом сознании тувинцев установки на ожидание помощи от других, в первую очередь, от государства и родственников, как о культурной особенности (Балакина, Кылгыдай, 2012; Анайбан, 2018: Электр. ресурс). Однако проведенный нами анализ достаточно ограничен и не позволяет сделать однозначный вывод о короткой или длинной дистанции власти у представителей тувинской этнической группы. По нашему мнению, дистанция в настоящее время сокращается - у старшего поколения сильнее выражена патерналистская установка (см.: Евразийский мир..., 2010: 215), а у младшего - начался переход к противоположной позиции. Но эта гипотеза требует дополнительной проверки.

Наконец, в том, что касается выраженности феминных или маскулинных ценностей у представителей тувинской этнической группы, отметим, что, как нам кажется, культура тувинцев скорее феминна, нежели маскулинна: 88\% считают, что в жизни сотрудничество и единство важнее, чем соперничество и борьба, а 64\% признаются, что для них важно работать в любимой профессии, даже если доход при этом будет небольшим. В пользу феминности рассматриваемой культуры также свидетельствуют заключения исследователей о склонности тувинцев к творческим профессиям, связанным с артистическим или художественным искусством (Анайбан, 2018: Электр. ресурс). В то же время, анализ ответов респондентов указывает также на выраженную ценность хорошего финансового обеспечения своего труда, что, как правило, считают характеристикой маскулинной культуры: 68\% ответили, что для них очень важно много зарабатывать, и при этом даже не важно, где именно. Фиксируя данное противоречие как симптом раскола системы ценностей у тувинской молодежи, мы можем говорить о ценности денег не только как характеристике маскулинности культуры, но также как об одном из маркеров современности, актуальном не только для тувинской культуры, но и далеко за пределами Тувы. Как отмечает 3. В. Анайбан, проблема труда и занятости молодежи (особенно сельской) является в Туве одной из наиболее острых. Справедливо ее заключение: «...молодые люди сегодня, в отличие от предыдущих старших поколений, социальные блага, материальные интересы все-таки ставят выше любых других ценностей» (там же), но происходит это не столько из внутренних ценностных установок, сколько из-за сложностей социально-экономического плана. При этом ориентация на финансовое благополучие у молодежи, разумеется, не является исключительно чертой Тувы: «желание денег как утопия будущего и своего благополучия» зафиксировано и исследователями Левада-центра при общероссийском опросе молодежи 2011 г. (Гудков, Дубин, Зоркая, 2011: 94).

Таким образом, можно заключить, что, по результатам анализа данных, тувинскую культуру следует относить к числу коллективистских, феминных культур с высокой степенью избегания неопределенности. Данный вывод позволяет сформулировать рекомендации, основанные на имманентных, подкрепленных на уровне культурных ценностей, характеристик производственной этики и особенностей менеджмента предприятий, которые могли бы быть полезны для улучшения экономических показателей Тувы.

В экономиках регионов с коллективистской культурой лучше развиваются предприятия, служащие которых связаны не только трудовым контрактом, но и моральными обязательствами по отношению друг к другу, эмоционально вовлечены в дела компании. В управлении приветствуется групповые решения, ценятся опыт и преемственность. Более успешны организации, «выращивающие» своих сотрудников для себя, корпоративная этика строится на основе принципа партикуляризма - деления окружающих на «своих» и «чужих». 
Ориентация культуры на высокую степень избегания неопределенности связана со значительным сопротивлением переменам у представителей культуры. В этой ситуации для развития бизнеса эффективно осуществление практик, связанных со строгим планированием деятельности организаций и введением детализированных требований и инструкций для сотрудников. Приветствуются организационные традиции и ритуалы. Взаимодействия между сотрудниками более успешны, если регламентированы взаимными правами и обязанностями - формально прописанными или неформальными, но ясными. Четкая иерархическая структура компаний в культурах с высокой степенью избегания неопределенности страхует их участников от случайностей и рисков. К особенностям организационной культуры относится то, что часто управленцев отбирают на основе критерия возраста и высокие посты занимают люди старшего возраста. Также отметим, что в таких культурах люди сложно переносят организационные конфликты.

В феминных культурах поощряются забота друг о друге и эмоциональная привязанность. Эффективным способом решения конфликта, в том числе делового, будут переговоры и достижение компромисса, а не борьба и противостояние. Корпоративная этика должна строиться на основе солидарности и скромности; считается справедливым распределение доходов на основе принципа равенства. В целом, представители такой культуры работают, чтобы жить, а не наоборот - живут ради работы. Отметим, что в приоритете успешных предприятий феминных культур находится забота о природе, бережное отношение к окружающей среде (Hofstede, 1980, 1998; Лебедева, Татарко, 2007; Оксинойд, 2013).

\section{Заключение}

Очевидно, что для поиска стратегий эффективного пространственного развития Тувы не только важно выявить специфику опирающихся на ценности этноэкономических укладов, но и решить ряд актуальных экономических и социальных вопросов. Часть из них напрямую связана с молодежью, особенно сельской. Эксперты отмечают, что в тувинских селах существенно ограничены возможности трудовой занятости молодых людей. Переезд в город также не решает проблемы: «весомую долю не имеющих работу образует сельская молодежь, которая активно пополняет ряды городских безработных» (Анайбан, 2018: Электр. ресурс). Молодежь - и сельская, и городская - оказывается в сложной ситуации как из-за недостатка трудового опыта, так и в связи со сложностями для значительной ее части найти свое место на рынке труда (там же).

В то же время, несмотря на все трансформации, которым подверглась система традиционных культурных ценностей тувинцев, у них до сих пор ценятся занятия традиционными видами хозяйствования, связанными с природой. Социологические опросы показали растущее число представителей тувинского этноса, которые хотели бы заниматься фермерством (Балакина, Кылдыгай, 2012 : 71). Нельзя не отметить, что возрождение и развитие сельского хозяйства осознается правительством Тувы и ее гражданским сообществом в качестве одной из приоритетных стратегий пространственного развития ${ }^{1}$. Такие сельскохозяйственные программы, как «Кыштаг для молодой семьи» и «Одно село один продукт» в сочетании со строительством и ремонтом сельских социальных объектов, дорог и инфраструктуры должны способствовать осовремениванию села, повышению его привлекательности для молодых. При этом фермерство как нельзя более соответствует духу феминной культуры и позволяет реализовывать модели производственной организации, свойственные коллективистской культуре - например, семейные предприятия. Представляется, что акцент на четком планировании деятельности организации, подробное инструктирование сотрудников об их обязанностях и введение в обиход организационных традиций (все это рекомендовано для менеджмента в культурах с высокой степенью избегания неопределенности) будут способствовать повышению доходов от фермерской деятельности. В этой связи важной стратегической задачей видится не только повышение профессиональных умений будущих индивидуальных фермеров, но и формирование их управленческих компетенций с учетом специфики ценностей тувинской культуры.

\footnotetext{
${ }^{1}$ Совет гражданских инициатив Тувы предложил дополнить проект Стратегии пространственного развития РФ до 2025 года [Электронный ресурс] // Тува Онлайн. URL: https://www.tuvaonline.ru/2018/11/30/sovet-grazhdanskih-iniciativ-tuvy-predlozhildopolnit-proekt-strategii-prostranstvennogo-razvitiya-rf-do-2025-goda.html (дата обращения: 1.03.2019); В Туве вступил в силу закон о бесплатной земле для переселенцев в малые села [Электронный ресурс] // Официальный портал Республики Тыва. URL: http://gov.tuva.ru/press_center/news/society/38759/ (дата обращения: 1.03.2019).
} 
Проведенный анализ позволяет дополнить социокультурный портрет пространственного развития Тувы такими ее чертами, как феминность, коллективистская ориентация, высокая степень избегания неопределенности. Представляется, что дальнейший поиск и разработка социокультурных особенностей региона будут способствовать решению важной для пространственного развития регионов задачи по учету этнокультурного фактора в социально-экономическом развитии субъектов Российской Федерации.

\section{Благодарности}

Автор выражает признательность за любезное согласие на использование для анализа статистических данных социологического исследования 2012 г., проведенного в Туве, руководителю проекта д. филос. н., проф. Ю. В. Попкову, а также координатору опроса канд. филос. н. С. А. Мадюковой.

\section{СПИСОК ЛИТЕРАТУРЫ}

Стратегия государственной национальной политики Российской Федерации на период до 2025 года [Электронный ресурс] // Президент России. URL: http://kremlin.ru/acts/bank/36512 (дата обращения: 01.06.2019).

Анайбан, 3. В. (2018) Трудовая занятость и социально-профессиональные ориентации молодежи современной Тувы [Электронный ресурс] // Новые исследования Тувы, № 2. URL: https://nit.tuva.asia/nit/ article/view/773 (дата обращения: 06.02.2019). DOI: 10.25178/nit.2018.2.6.

Аниканов, М. В., Степанов, В. В., Сусоколов, А. А. (1999) Титульные этносы Российской Федерации. Аналитический справочник. М. : Ин-т национальных проблем образования. 396 с.

Ахметов, В. Я., Бердникова, Г. И., Шагибалова, Г. И. (2010) Этноэкономика и сельское развитие: опыт локального исследования в этнически однородном территориальном сообществе // Региональная экономика: теория и практика. № 29. С. 36-42.

Балакина, Г. Ф., Кылгыдай, А. Ч. (2012) Особенности социально-экономической адаптации этнических групп в Республике Тыва // Социологические исследования. № 4 (336). С. 69-77.

Гонтарь, Н. В. (2015) Этноэкономика в контексте регионального развития: структурные особенности и характер влияния на социально-экономические процессы [Электронный ресурс] // Управление экономическими системами. № 11 (83). URL: http://www.uecs.ru/regionalnaya-ekonomika/item/3839-2015-11-3006-49-12 (дата обращения 11.02.2019).

Гудков, Л. Д., Дубин, Б. В., Зоркая, Н. А. (2011) Молодежь России. М. : Московская школа политических исследований. 96 с.

Дабиев, Д. Ф., Дабиева, У. М. (2015) Социокультурные процессы и экономика региона. О скорректированном показателе Индекса развития человеческого потенциала (ИРЧП) с учетом социокультурных факторов (на примере Тувы) // Экономический анализ: теория и практика. № 37. С. 50-64.

Евразийский мир: ценности, константы, самоорганизация (2010) / под ред. Ю. В. Попкова. Новосибирск : Нонпарель. 449 с.

Инглхарт, Р., Вельцель, К. (2011) Модернизация, культурные изменения и демократия: Последовательность человеческого развития. М.: Новое издательство. 464 с.

Киселева, Н. Н., Браткова, В. В. (2014) Проблемные регионы: сущность и идентификационные признаки // Вектор науки Тольяттинского государственного университета. № 4 (38). С. 131-135.

Колмакова, Е. М., Колмакова, И. Д., Дегтярева, Н. А. (2018) Пространственное развитие региона в контексте стратегии социально-экономического роста // Вестник Челябинского государственного университета. № 3 (413). С. 30-37.

Ламажаа, Ч. К., Абдулаева, М.Ш. (2014) Архаизация и неотрадиционализм: российские и региональные формы // Знание. Понимание. Умение. № 3. С. 68-80.

Ламажаa, Ч. К. (2011) Тува между прошлым и будущим. 2-е изд. СПб. : Алетейя. 368 с.

Лебедева, Н. М., Татарко, А. Н. (2007) Ценности культуры. М. : Издательский дом ГУ ВШЭ. 527 с.

Овчинников, В. Н., Колесников, Ю. С. (2006) Этноэкономика как фактор развития // Проблемы прогнозирования. № 1. С. 118-123.

Оксинойд, К. Э. Типология организационных культур Герта Хофстеда [Электронный ресурс] // Корпоративный менеджмент. URL: http:/www.cfin.ru/management/people/culture/Hofstede.shtml\# (дата обращения: 20.02.2019). 
Паникарова, С. В., Власов М. В., Чебодаев, В. П. (2011) Институты развития этноэкономики // Проблемы современной экономики. № 4. С. 53-57.

Персидская, О. А. (2012) Параметры сравнения культур Г. Ховстеде и Ф. Тромпенаарса: сходство и различия // Вестник Северного (Арктического) федерального университета. Серия: гуманитарные и социальные науки. № 5. С. 51-55.

Персидская, О.А. (2017) Этноэкономический уклад в жизнедеятельности регионального межэтнического сообщества // Сибирский философский журнал. Т. 15. № 1. С. 139-148.

Печура, О. В. (2009) Этнический фактор в развитии экономики региона // Известия Уральского государственного экономического университета. № 2 (24). С. 138-143.

Попков, Ю. В., Тюгашев, Е. А. (2010) Ценностные ориентации народов Южной Сибири // Евразийский мир: ценности, константы, самоорганизация / под ред. Ю. В. Попкова. Новосибирск: Нонпарель. 449 с. C. 213-236.

Тромпенаарс, Ф., Хэмпден-Тернер, Ч. (2004) Национально-культурные различия в контексте глобального бизнеса / пер. с англ. Е. П. Самсонова. М. : ООО «Попурри». 528 с.

Hofstede, G. (1980) Culture's Consequences: International differences in work related values. London, Sage Publications. 475 p.

Hofstede, G. (Ed.). (1998) Cross-cultural psychology series, Vol. 3. Masculinity and femininity: The taboo dimension of national cultures. Thousand Oaks, CA, US: Sage Publications, Inc. 256 p.

Schwartz, S.H. (1992) Universals in the content and structure of values: Theory and empirical tests in 20 countries / M. Zanna (ed.). Advances in experimental social psychology. N.Y.: Academic Press. Vol. 25. 397 p. P. 1-65.

Дата поступления: 01.06.2019 2.

\section{REFERENCES}

Strategiya gosudarstvennoy natsional'noy politiki Rossiyskoy Federatsii na period do 2025 goda [The strategy of the state national policy of the Russian Federation for the period up to 2025]. President of Russia [online]. Available at: http://kremlin.ru/acts/bank/36512 (accessed 28.06.2019). (In Russ.).

Anayban, Z. V. (2018) Trudovaya zanyatost' i sotsial'no-professional'nyye oriyentatsii molodezhi sovremennoy Tuvy [Employment and socio-professional orientations of contemporary Tuva's youth]. The New Research of Tuva, no. 2 [online] Available at: https://nit.tuva.asia/nit/article/view/773 (accessed date: 6.02.19). DOI: 10.25178/nit.2018.2.6 (In Russ.).

Anikanov, M. V., Stepanov, V. V. and Susokolov, A. A. (1999) Titul'nye etnosy Rossiiskoi Federatsii. Analiticheskii spravochnik [Titular ethnicities of the Russian Federation: An analytical reference book]. Moscow, Institute of National Problems of Education Publ. 396 p. (In Russ.).

Ahmetov, V. Ya., Berdnikova, G. I. and Shagibalova, G. I. (2010) Ethnoehkonomikai sel'skoe razvitie: opyt lokal'nogo issledovaniya $\mathrm{v}$ ehtnicheski odnorodnom territorial'nom soobshchestve [Ethnoeconomics and rural development: an attempt of a local study of an ethnically homogeneous territorial community]. Regional'naya ehkonomika: teoriya i praktika, no. 29, p. 36-42. (In Russ.).

Balakina, G. F. and Kyldygay, A. Ch. (2012) Osobennosti sotsial'no-ekonomicheskoy adaptatsii etnicheskikh grupp v Respublike Tyva [Socio-economic adaptation of ethnic groups in the Republic of Tyva]. Sotsiologicheskie issledovaniia, no 4 (336), pp. 69-77. (In Russ.).

Gontar', N. V. (2015) Ethnoehkonomika v kontekste regional'nogo razvitiya: strukturnye osobennosti i harakter vliyaniya na social'no-ehkonomicheskie processy [Ethnoeconomics in the context of regional development: structural features and the impact on the socio-economic processes]. Upravlenie ekonomicheskimi sistemami: elektronnyi nauchnyi zhurnal, no. 11 (83) [online] Available at: http://www.uecs.ru/regionalnaya-ekonomika/ item/3839-2015-11-30-06-49-12 (accessed date: 11.02.2019). (In Russ.).

Gudkov, L. D., Dubin, B. V. and Zorkaia, N. A. (2011) Molodezh' Rossii [Youth of Russia]. Moscow, Moskovskaia shkola politicheskikh issledovanii. 96 p. (In Russ.).

Dabiyev, D. F. and Dabiyeva, U. M. (2015) Sotsiokul'turnyye protsessy i ekonomika regiona. O skorrektirovannom pokazatele Indeksa razvitiya chelovecheskogo potentsiala (IRCHP) s uchetom sotsiokul'turnykh faktorov (na primere Tuvy) [Socio-cultural processes and the economy of the region. On the adjusted indicator of the Human Development Index (HDI), with relation to sociocultural factors (the case of Tuva)]. Economic Analysis: Theory and Practice, no. 37, p. 50-64. (In Russ.). 
Yevraziyskii mir: tsennosti, konstanty, samoorganizatsiia [Eurasian world: values, constants, self-organization] (2010) / ed. by Yu. V. Popkov. Novosibirsk, Nonparel' Publ. 449 p. (In Russ.).

Inglehart, R. and C. Welzel (2011) Modernizatsiya, kul'turnye izmenenia i demokratiya: Posledovatel'nost' chelovecheskogo razvitia [Modernization, Cultural Change, and Democracy The Human Development Sequence]. Moscow, Novoe izdatel'stvo Publ. 464 p. (In Russ.).

Kiseleva, N. N. and Bratkova, V. V. (2016) Problemnye regiony: suschnost' i identifikatsionnye priznaki [Problem regions: their nature and identification features]. Vektor nauki Tol'iattinskogo gosudarstvennogo universiteta, no. 4 (30), pp. 131-135. (In Russ.)

Kolmakova, E. M., Kolmakova, I. D. and Degtyareva, N. A. (2018) Prostranstvennoe razvitie regiona v kontekste strategii social'no-ekonomicheskogo rosta [Spatial development of a region in the context of a strategy of socio-economic growth]. Vestnik Cheliabinskogo gosudarstvennogo universiteta, no. 3 (413), pp. 30-37. (In Russ.).

Lamazhaa Ch. K. and Abdulaeva M. Sh. (2014) Arhaizatsiya i neotraditsionalizm: rossiiskie i regional'nye formy [Archaization and neotraditionalism: Russian and regional forms]. Znanie. Ponimanie. Umenie, no. 3, pp. 68-80. (In Russ.).

Lamazhaa, Ch. K. (2011) Tuva mezhdu proshlym i budushchim [Tuva between the Past and Future]. St. Petersburgh, Aletheia Publ. 368 p. (In Russ.).

Lebedeva, N. M. and Tatarko, A. N. (2007) Tsennosti kul'tury [Values of Culture]. Moscow, Higher School of Economics Publ. House. 527 p.

Ovchinnikov, V. N. and Kolesnikov, Yu. S. (2006) Etnoekonomika kak faktor razvitiia [Ethnoeconomics as a development factor]. Problemy prognozirovaniya, no. 1, pp. 118-123. (In Russ.).

Oksinoid, K. E. Tipologiya organizatsionnykh kul'tur Gerta Hofsteda [Geert Hofstede's typology of organizational cultures]. Corporate management [online] Available at: http://www.cfin.ru/management/people/culture/ Hofstede.shtml\# (accessed date: 20.02.2019). (In Russ.).

Panikarova, S. V., Vlasov, M. V. and Chebodaev, V. P. (2011) Instituty razvitiya etnoekonomiki [Institutes of development of ethnoeconomics]. Problemy sovremennoi ekonomiki, no. 4, pp. 53-57. (In Russ.).

Persidskaya, O. A. (2012) Parametry sravneniya kul'tur G. Hofstede i F. Trompenaarsa: skhodstvo i razlichiya [G. Hofstede's and F. Trompenaars' parameters of comparing cultures: similarities and differences]. Vestnik Severnogo (Arkticheskogo) federal'nogo universiteta. Seriia: gumanitarnye i sotsial'nye nauki, no. 5, pp. 51-55. (In Russ.).

Persidskaya, O. A. (2017) Etnoekonomicheskii uklad v zhiznedeyatel'nosti regional'nogo mezhetnicheskogo soobshchestva [Ethno-economic way of life in the regional inter-ethnic community]. Sibirskii filosofskii zhurnal, vol. 15, no. 1, pp. 139-148. (In Russ.).

Pechura, O. V. (2009) Etnicheskii faktor v razvitii ekonomiki regiona [The ethnic factor in the development of regional economy]. Izvestiia Ural'skogo gosudarstvennogo ekonomicheskogo universiteta, no. 2 (24), pp. 138-143. (In Russ.).

Popkov Yu. V. and Tyugashev Ye. A. (2010) Tsennostnyye orientatsii narodov Yuzhnoi Sibiri [Value orientations of the peoples of Southern Siberia]. In: Yevraziyskiy mir: tsennosti, konstanty, samoorganizatsiya [Eurasian world: values, constants, self-organization] / ed. by Yu. V. Popkov. Novosibirsk, Nonparel' Publ. 449 p. (In Russ.).

Trompenaars, F. and Hampden Turner, Ch. (2004) Natsional'no-kul'turnye razlichiia v kontekste global'nogo biznesa [Riding the Waves of Culture Understanding Cultural Diversity in Business]. Moscow, Popurri Rubl. 528 p. (In Russ.).

Hofstede, G. (1980) Culture's Consequences: International differences in work related values. London, Sage Publications. $475 \mathrm{p}$.

Hofstede, G. (Ed.). (1998) Cross-cultural psychology series, Vol. 3. Masculinity and femininity: The taboo dimension of national cultures. Thousand Oaks, CA, US: Sage Publications, Inc. 256 p.

Schwartz, S.H. (1992) Universals in the content and structure of values: Theory and empirical tests in 20 countries / M. Zanna (ed.). Advances in experimental social psychology. New York, Academic Press. Vol. 25. P. 1-65. 397 p.

Submission date: 01.06.2019. 